\title{
AN EXPLORATORY RESEARCH AMONG FASHION BUSINESS LEADERS AND NEUROMARKETING COMPANY EXECUTIVES ON THE PERCEPTION OF APPLIED NEUROMARKETING
}

\author{
DOI: 10.17261/Pressacademia.2020.1225 \\ JMML- V.7-ISS.2-2020(2)-p.72-80
}

\section{Ali Levent Kurtoglu ${ }^{1}$, Ali Murat Ferman ${ }^{2}$}

1 Isik University, Contemporary Management Studies, Maslak, Istanbul, Turkey ali.kurtoglu@isik.edu.tr, ORCID: 0000-0001-9597-9351

2.Beykent University, Rector, Maslak, Istanbul, Turkey. muratferman@beykent.edu.tr , ORCID: 0000-0002-1825-0097

Date Received: February 26, 2020

Date Accepted: May 12, 2020

To cite this document

Kurtoglu, A. L., Ferman, A.M., (2020). An exploratory research among fashion business leaders and neuromarketing company executives on the perception of applied neuromarketing. Journal of Management, Marketing and Logistics (JMML), V.7(2), p.72-80.

Permanent link to this document: http://doi.org/10.17261/Pressacademia.2020.1225

Copyright: Published by PressAcademia and limited licensed re-use rights only.

\begin{abstract}
Purpose- In the last two decades neuromarketing is considered to be an evolutionary concept within marketing that makes use of neuroscientific tools in order to measure human related factors such as attributes, emotions, memory and perceptions which influence the consumer decision making. The application of neuromarketing to various industries brings up new opportunities as well as new challenges. This purpose of this exploratory study is to shed light upon neuromarketing literature and to investigate the perception of neuromarketing and fashion executives towards applied neuromarketing in global and Turkish fashion industry.

Methodology- Following the up to date literature review about theoretical and applied neuromarketing, in-depth interviews with Turkish neuromarketing executives and fashion leaders are executed.

Findings- The findings show that there are discrepancies and similarities between the usage of applied neuromarketing in the globe and Turkey. In-depth interview findings show that the perceptions of Turkish fashion executives about neuromarketing differ from previous literature and different priorities exist to apply neuromarketing in fashion.

Conclusion- The findings are expected to help developing the collaboration of applied neuromarketing in fashion industry and support managerial decisions in marketing related resource allocations.
\end{abstract}

Keywords: Neuromarketing, fashion, perception, Turkey, in-depth interview. JEL Codes: C83, D89, M39

\section{INTRODUCTION}

The Importance of getting closer to the consumer in parallel to technological advancements has led marketing scientists and professionals to the search for seeking tools and methods to accomplish this. Meanwhile neuromarketing has gained popularity and related applications started to penetrate into various markets and industries in the last two decades. The desire to understand complex neural and emotional mechanisms that result in thoughts, perceptions, decisions and actions brought a variety of disciplines to work together (Perrachione, Perrachione, 2008). Like every brand-new concept it brought novelties as well as challenges to be defined, refined, explained and examined on both ends. On one hand neuromarketing companies, which supply industry counter parts with neuromarketing solutions, related results, action tactics and strategies, keep up with continuous exponential evolution of neuromarketing and on the other hand industries try to figure out how, where and when to benefit from this new platform. Among them neuromarketing and fashion, an indispensable priority for homo sapiens in the Maslow pyramid, 
got closer in the last few years. Despite fashion industry is based on fads and trends where all sensory stimuli may have a game changer role, the theoretical as well as the practical reflections are rare to find globally and locally.

Since early 2000s, neuromarketing has become a popular research area as well as a cross section of multidisciplines that strived for making sense of neuroscientifically collected meaningful data in terms of marketing. Having combined theories from not only traditional marketing but also economics and psychology, neuromarketing constituted the research problem itself or formed a vital method to reach to findings. Many industries such as fast-moving consumer goods (FMCG), telecommunications, banking, tourism etc. made use of these insights. Fashion industry among all remained rather shy although scientific findings did pull the industry into the exciting world of neuromarketing by stating one can love Louis Vuitton ads and be not aware of this fact (Ruanguttamanun, 2014).

This paper introduces the evaluation of the research problem and orientate the reader into the actual and potential relationships between neuromarketing and fashion. The literature review sheds light on foundations and actual state of neuromarketing with a global and local perspective. Profound methodology by referring to previous work and conducting in-depth interviews with Turkish neuromarketing and fashion business executives enable to reflect the perception of applied neuromarketing within the Turkish fashion industry and the ways how Turkish neuromarketing companies operate. Finally, the findings expand to new directions where priorities on both sides are emphasized and supply with conclusive remarks along with future pathways.

\section{LITERATURE REVIEW}

The idea that -conscious or nonconscious- all feelings, thoughts and behaviors are an outcome of neural activity was not even something to be dreamed of until last 3 decades. Even after the discovery of neuroimaging methods it was considered to be as an extravagant frontier science ( Harrell, 2019 ). Magnetic Resonance Imaging ( MRI) Technology is the first means that is used for measuring brain activity with the purpose of marketing in late 1990's where the terminology was first used by the Dutch Professor Ale Smidts (Phan, Wager, Taylor, Liberzon, 2002). At a parallel timestamp Zaltman et al. simultaneously took consumer researchers to a hike by advising to investigate further both on conscious and nonconscious mechanisms with the help of advancing technologies (Zaltman, 2000). However, it is not until 2004 that neuromarketing has received increasing recognition, interest, cross scientific interaction and reputation thanks to McClure et al. who showed the logics of branding within the human brain which is a black box (McClure et al., 2004). Fact based expression of the importance of subconsciousness decision making and how it plays a major role in consumer decision making are another brick on the wall constructed by Zurawicki et al. (Zurawicki, 2010).

Throughout the historical evaluation of neuromarketing which does not last back to very recent years there have been 2 major topics that are discussed:

\section{The Definition and understanding of neuromarketing}

\section{The Academical and commercial lay grounds of neuromarketing}

As far as the literature concerned the majority of the works are in pursuit of not creating solid scientific measurements-based contribution to practical and theoretical foundations but rather reviewing the data, seeking for superior definitions and synthesizing multidisciplinary items to express different views. The time window of these attempts is usually based on the famous experiment of McClure et al. in 2004 and afterwards where categorizations that are source to these definitions are based on different views such as used techniques, theoretical foundations, interpretations etc.

The difficulty in drawing solid lines for limitations and scope of neuromarketing definitions is obviously clear. The very fact that neuromarketing is forged in a multidisciplinary way shows up in the trials of the definitions which are laid down by scholars with different backgrounds thus different focus areas. Consequently, the subjectivity in the definitions of neuromarketing is understandable. Earlier interpretations tend to be based generally to limit neuromarketing with brain measurements which shifts to include central and peripheral nervous system in conjunction with marketing. On the other hand, the measurement outcomes about merely the efficiency in advertisement area tend to expand to a wider perspective of marketing definition penetrating to neuromarketing that cover pre-purchase, momentaneous stimulus and post purchase evaluations of consumers and how these affect consumer decisions making in terms of brand, brand loyalty and traditional 7Ps of marketing (Lim, 2018). Hence the hope and hype of neuroimaging are finding space for themselves in the definition of neuromarketing by referring to the idea of solution before it even existed (Ariely and Berns, 2010). 
Taking the evaluation of neuromarketing into account google trends show a fluctuating but a steady increase in the number of research requests, queries and publications. Another meta-analysis of neuromarketing studies used the search for neuromarketing in valid databases where 311 selected articles out of 394 between 2005 and 2017 are evaluated using cluster analysis and multi attribute decision making technique showed a similar result (Shahriari, Feiz, Zarei, Kashi 2019). The clusters for marketing strategies, Ads and Video Commercials, ethical issues, advertising message components, neuroscience in marketing, economics, consumer behavior, decision-making process and brand selection accumulate to the sum of the meta-analysis review where the popularity density is rather concentrated on marketing strategies with $32 \%$, ads and video Commercials with $25 \%$ and ethical issues with $17 \%$. However, the transitional change of interest in popularity density between the birth (2005-2011) and early ages (2012 - 2017) of neuromarketing related clusters marketing, economics and consumer decision making towards marketing strategies in a more and more digitalizing world is nothing but an awaited result. As far as the evolution of neuromarketing in Turkey is considered there are 28 post graduate thesis and 15 scientific articles written by researchers in Turkey where major contribution areas of these works address marketing, management and advertising disciplines (Sarı, Yılmaz, Ferik, 2019). In Parallel with the international trends due to the high cost and lack of qualified workforce the density is accumulated on timely shifted literature reviews, descriptions of methods, general surveys or application of low-cost neuroscientific measurement methods (Yücel and Coşkun 2018).

From a theoretical point of view before referring to commercialization of neuromarketing it should be explained that this is already one of the hot titles discussed between pro and anti-Neuromarketing supporters in the literature (Chark, 2018). As far as the terminology is concerned the question is whether neuromarketing should be considered as a branch of neuroscience that studies human behavior by benefiting from theoretical perspectives of consumer research or is it the consumer research itself contributing to the development of consumer theories by making use of neuroscientific methodologies (Plassmann et al., 2015). It is the first explanation that leans more towards neuroscience, medicine, psychology whereas it is the second part where the superior value is sought and delivered as far as marketing practices are performed by neuromarketing companies nowadays.

Within the classic marketing world there is always the urge and mutual request to deliver the superior value and to do that in a predictable, measurable and successful way. It is not new that many marketing campaigns with huge investments or new product solutions with high hopes do fail, resulting in negative return of investment (ROI) or even causing nonreturnable severe economic consequences (Castellion and Markham, 2013). The excessive numbers of companies in various markets and the technological rapid means of how consumers reach out to data, followed by consumption of the product/service solution contributes to marketeers evaluate what they have in their hands to benefit from more (Steven and Burley, 1997). Relatedly Krugman (1971) was one of the first marketeers who used EEG to analyze the relationship between brain activity. However, Gerald Zaltman and Stephen Kossyln were the first marketeers who had filed a patent for a neuroimaging tool that should validate whether an external stimulus provokes emotion, preference or predict and helps to predict consequences of the stimulus in a consumption or purchasing environment. That was the first commercial neuro-snowball rolled down from the top of the mountain (Hakim, Levy, 2018).

In the last decade neuromarketing has been the center of hope and the commercial starting point of many entrepreneurs and interested professionals with multidisciplinary professional backgrounds (Ariely and Berns, 2010). Though the hype is also there because of the lack of enough theoretical foundations (Plassmann et al., 2015), repeatable and numerous scientific experiments (Sarı, Yılmaz, Ferik, 2019) in global and local scale, procedural standards (Schneider and Woolgar, 2019), ethical issues (Stanton, Sinnott-Armstrong, Huettel, 2017). Despite that the growing interest, some successful solutions and the idea of limiting the rate of failure to a certain threshold supported the wide-spread of applied neuromarketing where industries such as gastronomy, product design (Spence, 2019) , automotive, ( Erk et al., 2002 ), FMCG (McClure, 2004; Kühn, Strelow, Gallinat, 2016 ), fashion ( Baldo, Parikh, Piu, Müller, 2015; Li, Wang, Wang, 2017), Hollywood (Christoforou, Papadopoulos, Constantinidou, Theodorou 2017) show interest in collaborating with commercial consumer research or better said neuromarketing companies. Among many applications, car companies show a rising interest in neuromarketing. Ford Motor Daimler Chrysler uses medical research tools to examine the ways how consumers think, Hyundai Motor uses EEG tests in the design process of the cars and measures the reactions of the consumers as part of the brand strategy, Toyota investigates whether it is possible to demonstrate that cognitive neuroscience can help to design multisensory warning signals for drivers that are significantly better than an engineer can come up with (Kumar and Singh, 2015; Spence, 2019). A recent study about car manufacturers in Europe shows that the expenditure for innovative marketing drops every year between 2009-2015 whereas Daimler's neuromarketing touch on the advertisement campaign grew their sales by $12 \%$ in 2017 and increased to profit up to $24 \%$. (Plakhin, Semenets, Ogorodnikova, Khudanina, 2018). Applied neuromarketing outcomes on film industry reflect that a Hollywood film's premiere performance can be predicted with

DOI: 10.17261/Pressacademia.2020.1225 
up to 23-fold increase when compared with prediction methods that use traditional methods (Christoforou, Papadopoulos, Constantinidou, Theodorou 2017). When it comes to fashion self-report and brain data prediction accuracy methods are compared in a case study and simulation based on a sales data which is based on self-report resulted in $12,1 \%$ increase of the company gross profit whereas brain-based prediction increased the profit to 36,4\% (Baldo, Parikh, Piu, Müller, 2015). Another publication is about the search to test consumer's willingness to pay more where fashion items are presented to the participants (Ramsøy, Jacobsen, Olivarius, Bagdziunaite, 2017) Fashion product design is the subject of another study where EEG and Eye tracking methods are used to demonstrate how human psychology and behaviors are affected by product appearance (Li, Wang, Wang, 2017) which is not reported to be used by a commercial company to the knowledge of this study.

In Turkey the actual number of published empirical neuromarketing studies with collaboration of commercial companies are very few. Interaction with commercial companies such as Vodaphone, Turkcell, Turkish Airlines, Denizbank etc. demonstrate that the global tendency and rising interest for discovering new methods are there for topics such as advertisement performance, brand loyalty, brand personality, packaging, consumer decision making (Girişken and Bulut, 2014; Çakır, Çakar, Girişken, 2015) however how this studies are translated into marketing strategies, how these are performed and what the related results can not be exemplified.

\section{DATA AND METHODOLOGY}

The Design of the methodology framework is carried out according to the goal that it meets the research objectives which are aligned with the overall research aim. The inductive research covers a literature review in multidisciplinary setup which deepens and sharpens with the addition of key opinion leaders' insights about the potential or existing relationship of fashion industry and neuromarketing companies. Although scientifically a positivist philosophy would benefit from working with observable social realities where the end product can be law like generalizations which are similar to those produced by the physical and natural scientist (Remenyi et al., 1998), the nature of the fact that neuromarketing is far from being formulized with thick border lines neither in theory nor in practice as well as the scarcity of applications in fashion industry require an interpretivist philosophy in alignment with the exploratory aim of this paper. In this regard the study advocates that it is necessary to understand the differences between humans in our role as social factors. Ontologically this brings the outcome that this work is socially constructed and subjective based on the literature review and in-depth interviews. Epistemologically the subjective meanings as well as the social phenomena behind the evolution of neuromarketing and the relationship between neuromarketing and fashion are investigated on a local perspective. As being a part of the topic what has been researched here the axiology is in alignment with the interpretivist philosophy. The inductive research approach throughout this work aims to gain a deeper understanding of the meanings with regard to neuromarketing and its applicability in fashion industry by collecting related qualitative data with less concern on formulating generalizations. As far as the research strategy is considered the purpose is to describe and explain the defined social world which consists of the subjects - neuromarketing and fashion business leaders - inhabit and that is what this ethnographic research strategy is firmly rooted in the inductive research approach. The research method encompasses multimethod qualitative studies including previous literature reviews, case application examples and in-depth interview. With the probability research sampling strategy, the chance and probability of each case which is selected from the population will be known and equal for all cases. Relatedly the research population is constituted according to the impracticability of covering the entire population, potential budget constraints and time scarcity of researched opinion leaders. Finally, the data that is used for this research is composed by using cross-sectional data collection methods between January-September 2019 with a limited time frame (Easterby-Smith et al., 2008) in the pursuit of exploring insights about the perception of neuromarketing and its applicability in fashion industry in Turkey.

In alignment with the way of usage of in-depth interviews as a qualitative method, the structure is designed to seek deep information and knowledge compared to what is sought in surveys, interviews and focus groups. It aims to promote reflecting personal matters, values and experiences, occupational ideology, perspective and concerns (Johnson and Rowlands, 2012). This is achieved by making use of previous research categorizations (Eser, Isin, Tolon, 2011) and structuring a 7 steps approach as depicted in Figure 1 (Kvale, 1996). 
Figure 1: In-depth Interview Process

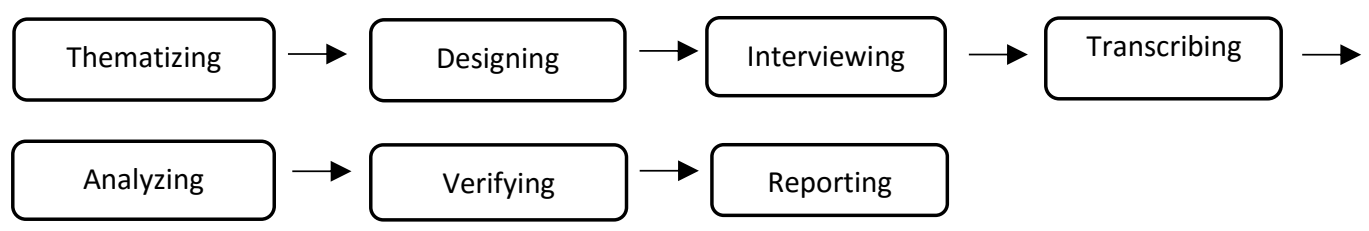

In pursuit of finding the answers of research objectives the questions in the design of the interview are constructed in a way to elicit this information through the interview structure. Thus, categorizations and amounts of questions for cross-checking purposes to obtain information are reflected in Table 1.

2 sets of in-depth interviews are applied to 8 members of the target audience where the purpose of the interview is processed in the thematizing section. Remarkably although the total amount of questions is 18 in the interviews, several questions included motives belonging to another question category under business experience and background with a focus on marketing, knowledge about neuromarketing, willingness to make use of neuromarketing research, conducting neuromarketing research for different industries and ethical concerns to test the validity of previous given information and find out relevant possible attention points if there are any. Except the questions where the demographic Info is retrieved all of the questions are formed as openended so that the respondents have the possibility to expose their views and provide with detailed opinions on the chosen topics which prevent them from answering with a mere yes or no. The semi-structured form is chosen to contribute to the conversational flow of the interview so that the respondents do not feel they are being interrogated. For every Interview

Table 1: Categorizations of In-depth Interview Questions

\begin{tabular}{|lc|}
\hline Categorization & $\begin{array}{c}\text { Number of } \\
\text { Questions }\end{array}$ \\
\hline Demographics & 3 \\
Business experience and background with a particular focus on marketing & 6 \\
Knowledge about neuromarketing & 4 \\
Willingness to make use of neuromarketing research & 6 \\
Willingness to conduct neuromarketing research for different industries & 6 \\
Ethical concerns & 6 \\
\hline
\end{tabular}

a face sheet which included time, date and place of the Interview is used along with a post-interview comment sheet where additional notes such as feelings, interpretations and similar comments are provided (Boyce and Neale, 2006). The responses are recorded via voice recorder application and transcribed manually via listening and transferring into written form. In the analyzing section content analysis is performed which is followed by triangulation with the literature review and reconfirmation of the responses from the respondents.

The sampling size for neuromarketing companies is chosen to include all hits on Google as they are all geographically in the same city where the study is performed, and no distinction or sub selection is applied in terms of any specific neuromarketing method or interested business area these companies are working in. The sampling size for the fashion industry respondents is chosen according to the independent brand evaluation reports of Brand Finance that are published in 2016, 2017 and 2018.

\section{FINDINGS AND DISCUSSIONS}

Findings show that the variety of applied neuromarketing measurement tools and methods, industries collaborated or worked with and academical contributions on a global vs local comparison yield strongly in favor of the global side. Not only the literature review but also in-depth interview results confirm this finding. According to the findings there are preliminary neuromarketing 
studies executed for fashion industries on a global scale whereas the tools and previous works in other industries promise various aspects of marketing and business strategy to be studied and optimized for fashion via making use of neuromarketing. Referring to the in-depth interview results the level of neuromarketing knowledge and relatedly the neuromarketing experience in Turkish fashion industry are very low and limited to personal efforts of participants. However, the eagerness to learn more about neuromarketing is remarkable yet limited due to daily dynamics and expectations of business. Thus, Turkish fashion key executives do not know exactly what to expect which makes the assessment for a potential readiness difficult. There is one example where one Turkish fashion company initiated to make use of neuromarketing in the optimization of TV Advertisements for raising the awareness and level of attention of the spectators. There is a wide spectrum of industries where neuromarketing companies work actively with on brand loyalty, package design, brand identity, sales effectiveness in Turkey. Banking, telecommunication and FMCG are expressed as the prominent industries. The intersection of supply and expected demand in terms of neuromarketing is limited with a one-way direction driven by the neuromarketing company itself except if there is a commercial entity approaching a Turkish neuromarketing company wondering what and how to improve their marketing approach by using neuromarketing methods. There, key executives of neuromarketing companies express that methods are applicable for any desired setting and can be configured accordingly. However due to seasonal budget restrictions of commercial companies and pressure on sustaining the business, the choice is rather to proceed with either companies that have already made use of neuromarketing previously or if there is already a background knowledge about potential improvable aspects of that specific company or business on the neuromarketing side. The business models and operations of neuromarketing companies vary in the way the services are supplied. In-depth interview results show that the provided services can be based either on existing data that is gathered as a result of secondary research and consultative personalized solutions are formed up for the existing problem or the services can be based on personalized research and related solutions. The perception of neuromarketing is not consistently positive as it was found out in previous studies (Eser, Isin, Tolon, 2011 ) among the participants from fashion industry however this is sourced due to the limited exposure and not having the right time window to investigate, test and implement it into their operations which is also in alignment with the wider literature review. There are certain drivers and priorities for both sides in order to collaborate with a commercial company or apply neuromarketing in the fashion industry shown in Table 2 below. Turkish neuromarketing companies prioritize prior knowledge about the specific industry, past experience with the same company, a counterpart which asks the right

Table 2: Content Analysis

\begin{tabular}{|c|c|c|c|}
\hline Categorization & $\begin{array}{l}\text { Compiled } \\
\text { Outcome }\end{array}$ & $\begin{array}{l}\text { Neuromarketing } \\
\text { Executives }\end{array}$ & $\begin{array}{c}\text { Fashion Business } \\
\text { Executives }\end{array}$ \\
\hline Demographics & $\begin{array}{l}\text { No particular } \\
\text { difference }\end{array}$ & $\begin{array}{l}\text { Mean age: } 33 \text { / } \\
\text { Females: } \% 66\end{array}$ & $\begin{array}{l}\text { Mean Age: } 54 / \\
\text { Males: } \% 80\end{array}$ \\
\hline $\begin{array}{l}\text { Business experience and background with a } \\
\text { particular focus on marketing }\end{array}$ & $\begin{array}{c}\text { Particular } \\
\text { Differences }\end{array}$ & $\begin{array}{l}\text { Marketing-centered, } \\
\text { originated from } \\
\text { diverse occupations }\end{array}$ & $\begin{array}{l}\text { Family enterprises } \\
\text { that make use of } \\
\text { corporate marketing } \\
\text { trends with } \\
\text { professional teams }\end{array}$ \\
\hline Knowledge about neuromarketing & $\begin{array}{c}\text { Particular } \\
\text { Differences }\end{array}$ & $\begin{array}{l}\text { Educated / Self- } \\
\text { thought }\end{array}$ & Low / Self - Efforts \\
\hline $\begin{array}{l}\text { Willingness to make use of neuromarketing } \\
\text { research }\end{array}$ & $\begin{array}{l}\text { Particular } \\
\text { Differences }\end{array}$ & $\begin{array}{c}\text { Strong commercial / } \\
\text { moderate academic } \\
\text { interest }\end{array}$ & $\begin{array}{l}\text { High willingness/ } \\
\text { Skeptical }\end{array}$ \\
\hline $\begin{array}{l}\text { Willingness to conduct neuromarketing research } \\
\text { for different industries }\end{array}$ & $\begin{array}{l}\text { Particular } \\
\text { Differences }\end{array}$ & $\begin{array}{l}\text { High, if priorities are } \\
\text { fulfilled }\end{array}$ & $\begin{array}{l}\text { Moderate towards } \\
\text { high if priorities are } \\
\text { fulfilled }\end{array}$ \\
\hline
\end{tabular}


Moderate

Differences
Moderate, assured by

existing regulations
High, concern for

current brand

communication

right questions and ethical alignment with the client whereas Turkish fashion business executives do prioritize ethical and transparent approach, efficient return of investment, alignment with existing marketing communication strategies and flowless integration into continuing operations.

\section{CONCLUSION}

To the knowledge of the authors this was the first and only academic research that concentrated on neuromarketing and fashion as core objects on a global and Turkish setting. As a consequence of the research's factual nature and the methodology used to reach the goal of the work, induced outcomes are delivered. The work acknowledges previous research in the field of perception about neuromarketing including different professions and different perspectives and contributes with the findings of leading neuromarketing and fashion business leaders 'point of views supported by up to date literature review with this focus.

The research faced several challenges where some of them were expected due to the choice of exploratory research and related methodology. It is clear that the nature of this research is inductive and thus it involves the merging of primary and secondary data where the primarily collected data is based on in-depth interviews with key neuromarketing and fashion executives in Turkey which has also consequences as far as the limitations are concerned. First, as a result of its nature this study can not be referred as generalizable. Although the sample represents the top 5 fashion brands in Turkey within the last 3 consecutive years and 75\% of Turkish neuromarketing companies that are physically accessible after secondary research, the variety of fashion companies in terms of scale and classification as well as the neuromarketing divisions of already existing advertisement agencies in Turkey present a wider platform which needs to be taken into account for wider generalizability. Secondly the choice of using in-depth interview created the challenge to cope with the time schedules of the executives which resulted in major difficulties to reaching out the high-level participants, several postponements, squeezed or prolonged sessions. Apart these technical challenges and limitations, because of the way how in-depth interview results are decoded and transcribed, the results are naturally subjective and prone to bias. Thirdly one major limitation is because of the choice of exploratory research which is in alignment with the aim of the study along with the research aim and the uncharted area of the status of Turkish neuromarketing companies, applied neuromarketing in Turkey and the approach of Turkish Fashion companies towards neuromarketing.

Comparing global literature findings and local in-depth interview findings, it is visible that globally the neuromarketing tools and applications are used much more effectively usually with mid-term profit maximizing purposes whereas locally even the existence and meaning of neuromarketing is missing. As far as Turkish fashion market is considered, hypothetically the desire for the sustainable partner relationship between the consumer and the brand is present and practically traditional marketing methods along with online and digital marketing tools are used effectively to realize this purpose. However mature markets, investigated in the literature, within different geographies and on different sectors show similar patterns at point of initiation for integrating applied neuromarketing into commercial entities 'operations. On the other hand, privacy statements and user information confidentiality regulations that are applicable for the creation of digital big data and used currently by commercial companies constitute a clear way to depict consumer decision patterns without conscious consent of the users as it was filmed in the movie "The Great Hack". Therefore, in an environment where conscious consent of participants is asked and full transparency over the processes and outcomes are enabled any doubts or suspicions along with misperceptions should be erased and neuromarketing can be applied for each and every industry where human emotions and attitudes are present.

This study discovered 5 different directions the research can be extended and expanded. Perceptions based on the usage of traditional methods in fashion can be cross tested with neuromarketing methods. Celebrity effect, outcomes of participating in a social event as a brand, gender dependent product-place-brand perceptions are only some of the topics that have similar academic references. All these applied techniques should contribute to the efficiency of return of investment on the fashion side, to the development of academic knowledge on the neuromarketing side and to the extension of neural correlates or attributes that are related to consumer decision making on the marketing theory side. Secondly the initial steps that are taken globally to apply neuromarketing in fashion should be started in Turkey as well. Future research on place design optimization, measurement of customer post purchase reactions and neuro-inspired product designs seem to be the most relevant and available application areas expressed by the Turkish fashion key opinion leaders. Neuromarketing techniques and applications can be two different or 
one merged future research direction. As far as techniques are concerned documentation of differentiated usage of method such as fNIR shall be documented and published globally to constitute the standard for its usage. Moreover, other used methods shall be applied at different industries, documented and published to extend the academic knowledge. The effects of not disclosing the applications, processes and the outcomes on the perception of neuromarketing by the public and various industries present themselves as empirical findings which can be further studied. Finally, it is mentioned in the literature several times in different forms that neuromarketing receives a lot criticism due to its young age. Therefore, especially future research on laying out global and local ethical standards and regulations to clarify any suspicion on consumer manipulation and to remove the lack of transparency are the recommended research directions.

\section{REFERENCES}

Ariely,D., Berns, G.S. (2010). Neuromarketing: The hope and hype of neuroimaging in Business. Nature Reviews Neuroscience, Volume 11(4): 284292.DOI: $10.1038 / \mathrm{nrn} 2795$

Baldo, D., Parikh, H., Piu, Y., \& Müller, K.-M. (2015). Brain Waves Predict Success of New Fashion Products: A Practical Application for the Footwear Retailing Industry. Journal of Creating Value, 1(1): 61-71. DOI: 10.1177/2394964315569625

Boyce, C., Neale, P. (2006). Conducting in-depth interviews: A guide for designing and conducting in-depth interviews for evaluation input: Pathfinder International Watertown, MA

Castellion, G., Markham, S. K. (2013). New Product Failure Rates. Journal of Product Innovation Management, Volume 30(5): 976-979. DOI: 10.1111/j.1540-5885.2012.01009.x

Chark, R. (2018). Neuromarketing, Innovative Research Methodologies in Management. Palgrave Macmillan, Cham.

Christoforou C., Papadopoulos T.C., Constantinidou F., Theodorou M. (2017). Your Brain on the Movies: A Computational Approach for Predicting Box-office Performance from Viewer's Brain Responses to Movie Trailers. Front. Neuroinform. 11: 72. DOI: 10.3389/fninf.2017.00072

Cakir, M. P., Cakar, T., Girisken, Y. (2015). Neural Correlates of Purchasing Behavior in the Prefrontal Cortex: An Optical Brain Imaging Study. Cognitive Science Society Annual Meeting: 297-302

Easterby-Smith, M., Thorpe, R., Jackson, P., Lowe, A. (2008). Management Research 3rd edition, London, Sage

Erk, S., Spitzer, M., Wunderlich, A. P., Galley, L., Walter, H. (2002). Cultural objects modulate reward circuitry. NeuroReport, Volume 13(18): 24992503. DOI: 10.1097/00001756-200212200-00024

Eser, Z., Isin, F. B., Tolon, M. (2011). Perceptions of marketing academics, neurologists, and marketing professionals about neuromarketing. Journal of Marketing Management, Volume 27(7-8): 854-868. DOI: 10.1080/02672571003719070

Girişken,Y., Bulut,D. (2014). How do consumers perceive a/an logotype/emblem in the advertisements: An eye tracking study. International Journal on Strategic Innovative Marketing, Volume 01: 198-209. DOI: 10.15556/IJSIM.01.04.002

Hakim, A., Levy, D.J. (2018). A gateway to consumers' minds: Achievements, caveats, and prospects of electroencephalography-based prediction in neuromarketing. Wiley Interdisciplinary Review, Cognitive Science, Volume 10(2): e1485 DOI: 10.1002/wcs.1485

Harrell, E. (2019). Neuromarketing what you need to know. Retrieved from https://hbr.org/2019/01/neuromarketing-what-you-need-to-know

Johnson, J., Rowlands, T. (2012). The interpersonal dynamics of in-depth interviewing. In Gubrium, J. F., Holstein, J. A., Marvasti, A. B., McKinney, K. D. The SAGE handbook of interview research: The complexity of the craft, Thousand Oaks, CA: SAGE Publications

Krugman, H. E. (1971). Brain wave measures of media involvement. Journal of Advertising Research, Volume 11(1): 3-9

Kühn S., Strelow E., Gallinat J. (2016). Multiple "buy buttons" in the brain: Forecasting chocolate sales at point-of-sale based on functional brain activation using fMRI. Neuroimage, Volume 136: 122-128. DOI: 10.1016/j.neuroimage.2016.05.021

Kvale, S. (1996). Interview Views: An Introduction to Qualitative Research Interviewing. Thousand Oaks, CA: Sage Publications.

Li, Bao-Rui, Wang, Y., Wang, Ke-Sheng (2017). A novel method for the evaluation of fashion product design based data mining. Advances in Manufacturing, Volume 5(4):370-376. DOI: 10.1007/s40436-017-0201-x

Lim, W.M. (2018). Demystifying neuromarketing. Journal of Business Research, Volume 91(C): 205-220. DOI: 10.1016/j.jbusres.2018.05.036 
McClure, S.M., Li, J., Tomlin, D., Cypert, K.S., Montague, L.M., Montague, P.R. (2004). Neural correlates of behavioral preference for culturally familiar drinks. Neuron, Volume 44(2): 379-387. DOI: 10.1016/j.neuron.2004.09.019

Perrachione, T.K., Perrachione, J. (2008). Brains and brands: developing mutually informative research in neuroscience and marketing. Journal of Consumer Behaviour, Vol. 7(4-5): 303-318. DOI: 10.1002/cb.253

Phan, K.L., Wager, T., Taylor, S.F., Liberzon, I. (2002). Functional neuroanatomy of emotion: A meta-analysis of emotion activation studies in PET and fMRI. Neuroimage, Volume 16(2): 331-348. DOI: 10.1006/nimg.2002.1087

Plakhin, A., Semenets, I., Ogorodnikova, E., Khudanina, M. (2018). New directions in the development of neuromarketing and behavioral economics. MATEC Web of Conferences, Volume 184:1-6. DOI: 10.1051/matecconf/201818404023

Plassmann, H., Venkatraman, V., Huettel, S., Yoon, C. (2015). Consumer Neuroscience: Applications, Challenges, and Possible Solutions. Journal of Marketing Research, Volume 52(4): 427-435. DOI: 10.1509/jmr.14.0048

Ramsøy, T.Z., Jacobsen, C., Friis-Olivarius, M., Bagdziunaite, D., Skov, M. (2017). Predictive Value of Body Posture and Pupil Dilation in Assessing Consumer Preference and Choice. Journal of Neuroscience Psychology and Economics, Volume 10(2-3): 95-110. DOI: 10.1037/npe0000073

Remenyi, D., Williams, B., Money, A., Swartz, E. (1998). Doing research in business and management: An Introduction to Process and Method. London, Sage

Ruanguttamanun, C. (2014). Neuromarketing: I Put Myself into a fMRI Scanner and Realized that I love Louis Vuitton Ads. , Procedia - Social and Behavioral Sciences, Volume 148: 211-218. DOI: 10.1016/j.sbspro.2014.07.036

Sarı,B., Yılmaz,B., Ferik A.O. (2019). Pazarlama araştırmalarında yeni bir eğilim olarak nöropazarlama: Türkiye'de nöropazarlama alanında yapılan akademik çalışmalara yönelik bir inceleme, Selçuk İletişim, 12 ( 2 ):1127-1168. DOI: 10.18094/JOSC.596326

Schneider, T., Woolgar, S. (2019). Witness and Silence in Neuromarketing: Managing the gap between science and its application. Science, Technology and Human Values, 45(1): 1-25. DOI: 10.1177/0162243919829222

Simmons, B. (2015, January 9). The tale of two Flaccos. Retrieved from http://grantland.com/the-triangle/the-tale-of-two-flaccos/

Singh, P., Kumar, H. (2015). Neuromarketing: An emerging tool of Market Research. International Journal of Engineering Business Management, Volume 5(6): 530-535.

Spence, C. (2019). Neuroscience-Inspired Design: From Academic Neuromarketing to Commercially Relevant Research. Organizational Research Methods, Vol. 22(1): 275-298. DOI: 10.1177/1094428116672003

Stanton, S. J., Sinnott-Armstrong, W., Huettel, S. A. (2017). Neuromarketing: Ethical implications of its use and potential misuse. Journal of Business Ethics, 144(4): 799-811. DOI: 10.1007/s10551-016-3059-0

Stevens, G., A., Burley, J. (1997). 3,000 Raw Ideas = 1 Commercial Success! Research-Technology Management, Volume 40(3): 16-27. DOI: $10.1080 / 08956308.1997 .11671126$

Yücel, A., Coşkun, P. (2018). Nöropazarlama Literatür İncelemesi. The Journal of International Social Sciences, Volume 28(2): 157-177. DOI: 10.18069/firatsbed.460933

Zaltman, G. (2000). Consumer researchers: Take a hike! Journal of Consumer Research, Vol. 26(4): 423-433. DOI: 10.1086/209573

Żurawicki, L. (2010). Neuromarketing: Exploring the brain of the consumer. Springer, Heidelberg 